\title{
EVALUATION OF THERMAL INSULATION PERFORMANCE OF PERLITE EXPANDED PARTICLES
}

\author{
Hadeer Mahmood Yahya \\ hadeer94.1994@gmail.com \\ Karima Esmail Amori \\ drkarimaa63@gmail.com \\ University of Baghdad- College of engineering-Department of Mechanical engineering
}

\begin{abstract}
The aim of this work is to test the effectiveness of new thermal insulation material formed from semi-spherical Perlite expanded particles for liquefied petroleum gas (LPG) tanks. Five different samples of semi-spherical particles of $(68.8,90.4,300.5$, $1211000,1861000) * 10^{-9} \mathrm{~m}$ diameter are used as a new thermal insulating material in this work. To simulate the LPG tank wall, a stainless-steel plate of a thickness $(3 \mathrm{~mm})$ is coated with this material and subjected to a resistive type flat plate heater. The thermal insulation coating thickness was $(0.5 \mathrm{~mm}$ to $2 \mathrm{~mm})$. This plate is subjected to different power loads namely $\left(650,1260 \mathrm{~W} / \mathrm{m}^{2}\right)$. Results show that increasing the insulation expanded particle size increases the difference in temperatures on both sides of the insulation layer. The first three sizes of the insulation material reported a temperature difference at both sides of the coating layer is about $18{ }^{\circ} \mathrm{C}$, while that for the fourth and fifth size are $20{ }^{\circ} \mathrm{C}$ and $25{ }^{\circ} \mathrm{C}$ respectively since larger expanded particles size has higher air content that enables them to reduce and delay heat transfer. The thermal conductivity of coated thermal insulation with large Perlite particle size is $(0.25 \mathrm{~W} / \mathrm{m} . \mathrm{K})$, while that for small size is $(0.42 \mathrm{~W} / \mathrm{m} . \mathrm{K})$. The previously reported thermal conductivity for Silica granules is less than $0.4 \mathrm{~W} /(\mathrm{m} . \mathrm{K})$ for insulation thickness of $(50 \mathrm{~mm})$, while that for binderless cotton stalk fiberboard (BCSF) is ranged from 0.0585 to $0.0815 \mathrm{~W} / \mathrm{m} \mathrm{K}$ for board thickness $25 \mathrm{~mm}$. The indicated thermal conductivity for coconut husk and bagasse insulation boards is 0.046 and $0.068 \mathrm{~W} / \mathrm{mK}$ for board thickness $25 \mathrm{~mm}$. So utilizing Perlite expanded particles as an insulation material is superior since it is a slim layer not exceeded $2 \mathrm{~mm}$.
\end{abstract}

Keywords: thermal insulation, Perlite, LPG tank, heat transfer, conductivity

$$
\text { تقييم اداء العزل الحراري لجسيمات البيرلايت المنتفخة }
$$

|نخلاصة

الهدف من هذا العمل هو اختبار فعالية العزل الحراري لمادة التهادة جديدة مكونة من جسيمات البيرلايت شبه الكروية المنتفخة

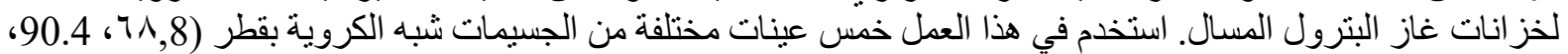

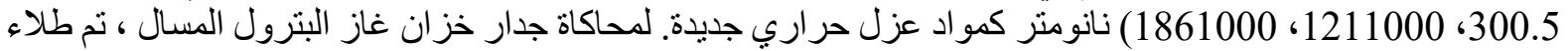

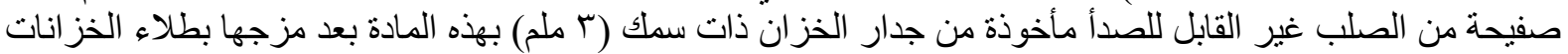

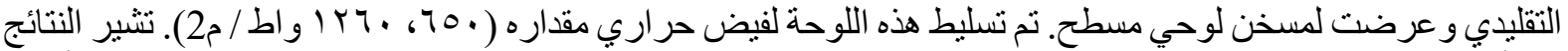

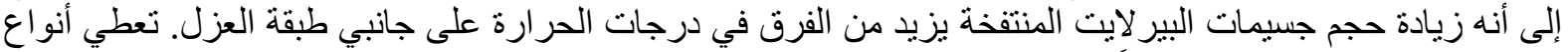

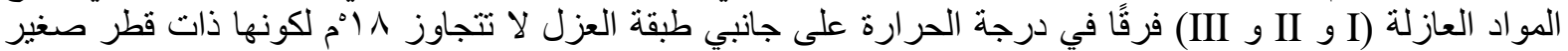

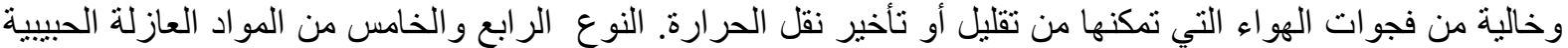

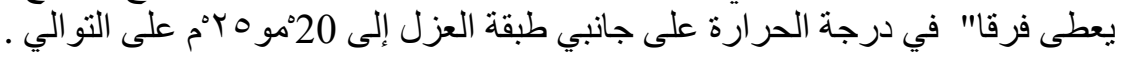




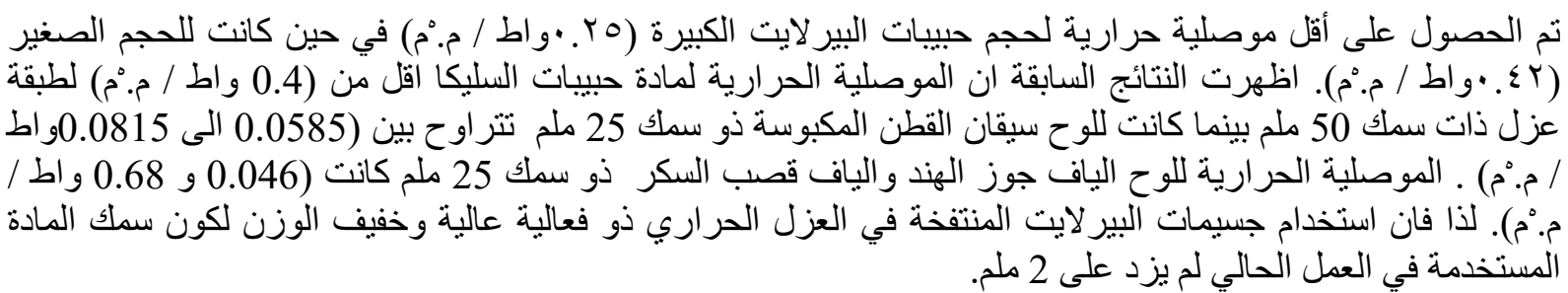

\section{NOMENCLTURE}

Symbol Description

$\Delta \mathbf{T} \quad$ The temperature difference

A Cross-sectional area $\left(\mathrm{m}^{2}\right)$

BCSF Binderless Cotton Stalk Fiberboard

BLEVE Boiling Liquid Expanding Vapor

Explosions

I Current (A)

$\mathrm{K} \quad$ Thermal conductivity $\left(\mathrm{W} / \mathrm{m} .{ }^{\circ} \mathrm{C}\right)$

$\mathrm{L} \quad$ The thickness of the coated layer

(m)

LCI Layered Composite Insulation

LNG Liquefied Natural Gas

LPG Liquefied Petroleum Gas

MLI Multilayer insulation

$\mathrm{P} \quad$ Power (W)

PVC PolyVinylChloride

Q Heat flux $\left(\mathrm{W} / \mathrm{m}^{2}\right)$

SEM Scanning Electron Microscope

SOFI Spray-On Foam Insulation

$\mathrm{V}$

The voltage difference of the heater

(V)

VDMLI Variable Density Multilayer

Insulation

XRD X-Ray Diffraction

\section{INTRODUCTION}

A crucial issue to ensure temperature control, safety and reliability of LPG storage tanks are its internal controlled conditions (temperature and pressure) by eliminating their heat addition and rejection with ambient using the appropriate thermal insulation. Thermal insulation refers to all insulating systems and processes that limit heat exchange at different temperatures. It is a material or group of materials when applied correctly delays or reduces the gain or heat loss by conduction, convection, and radiation depending on engineering application, such as buildings, power generation, air conditioning, and food processing, ventilation ducts, the oil industry, etc. Thermal insulation materials can be classified as fiber insulation, foam insulation, multilayer insulation (MLI), and vacuum space. Many researchers studied insulating materials, Droste and Schoen (1988) designed and investigated the thermal insulation for(LPG) storage tank against external thermal impacts to prevent its failure. Thermal insulation 
fibers (mineral wool material) stitched with steel wire (a commercial name I SOVER MD2) is used as thermal insulation for a horizontal cylindrical LPG tank. Results showed that the non-protected tank failed after exposed it to a period of burning between 7 to 12 minutes causing boiling of a liquefied gas then expanding vapor explosion because of the increased internal overpressure. Layered Composite Insulation (LCI) system is adopted by Fesmire (2016) for thermal insulating of cryogenic tanks or Liquefied Natural Gas (LNG) storage tanks. The common elements of this insulating system are a primary insulated blanked layer, a layer of compressible radiant barrier, and an overwrap layer. Results show that this insulating system is suitable to insulate tanks of temperatures of $4 \mathrm{~K}$ to $400 \mathrm{~K}$ under extreme ambient exposure conditions. A thermodynamic model was developed by Joseph et al. (2017) to understand the influence of the thickness of the foam insulation material on the development of the liquefied thermal stratification of the liquefied pressurized tank. Results showed that reduction of the thickness of the insulation leads to raising the tank pressure significantly, which also leads to an increase in stratified mass. Landucci et al. (2009)presented a finite element model to assess the time of failure and thermal protection response of spherical and horizontal cylindrical LPG tanks in accidental fire engulfment to avoid Boiling Liquid Expanding Vapor Explosions BLEVE. Different types of protective coatings are studied name: intumescing, mineral cement and rock wool of thicknesses of $(10,38$ and $100 \mathrm{~mm})$ respectively. Results confirmed that intumescing resulted in better performance while fibrous wool or cementitious formulations appeared not effective at the same level allowing stress increase among the vessel shell. Correlations are developed for tank time failure with effective coating thickness. Thermal and mechanical model of propane (LPG) storage vessels is explored by Landucci et al. (2009) to figure the effect of four different insulation materials used as a coating layer on the vessel subjected to an accidental fire. The finite element model is adopted and verified with experimental tests. The coating insulation performance and the failure time are assessed when the vessel is coated with epoxy intumescent, or vermiculite spray, or fibrous mineral wool or Cementitious inorganic formulation. They found that the thermal coating greatly increases the failure time. Also, results show the best thermal insulation is that of inherent lower thermal performance that limits the vessel wall heat transfer, (it was vermiculite spray in this work). A new thermal insulation system was designed and discussed by Niu et al. (2017) of the new independent type B CCS. The results showed that this type of insulation is considered easy to inspect and repair. It also can withstand mixing loads at any filling level in the tank in case of shipping. Paltrinieri et al. (2009) investigated and adopted passive fire protection, to reduced LPG transportation riskiness. Rock wool and organic intumescing were used as thermal coatings. Results showed that the non-insulated reservoirs failed after 20 minutes and the isolated reservoirs failed after 100 minutes. The fire protection materials reduced the risk ratio by $50 \%$. The effect of the protective layer of PolyVinylChloride PVC resin was investigated and analyzed by Sun et al.(2013) on the LPG vessel. The time required to reach vessel failure was increased rapidly with increasing the protective layer thickness, also the pressure rise is decreased significantly. Zheng et al. (2018) studied theoretically and experimentally multilayer insulation (MLI)/ Variable Density Multilayer Insulation (VDMLI) and the composite insulation system of Spray-On Foam Insulation (SOFI). The results showed 
with 50 reflector layers, heat leakage through VDMLI is lower than of MLI by $13.53 \%$, and heat flux through VDMLI is lower than that of MLI by $17.49 \%$.

The aim of this study is to test the thermal insulation performance for a novel thermal coating layer. This layer is formed of a perlite expanded particles mixed with resin paint to coat a sample of steel plate taken from the LPG tank. The size effect of perlite expanded particle size and the subjected heat flux are investigated to specify the best size of Perlite particle used as insulating material. Up to the author's knowledge, unprecedented material is used to thermally insulate for the LPG tank wall in Iraq.

\section{EXPERIMENTAL WORK}

\section{Experimental Setup}

The components of the experimental setup shown in figure $(1, a, b)$ include a resistive type flat plate heater, samples of LPG tanks wall, the adopted thermal insulation samples, voltage variation device (variac), voltmeter, ammeter, and temperatures instruments. The heater consists of five cartridge heater (resistive type) of diameter (10 $\mathrm{mm})$, and length $(100 \mathrm{~mm})$. It is installed internal an aluminum plate to form a flat heating plate heater (heat source) gives approximately $20 \mathrm{~W}$ at full load. In the upper wall of the test section, five holes of $1 \mathrm{~mm}$ bore are drilled to measure it's temperature as shown in figure (2). The sample form (LPG) tank wall of dimensions (100*100*3 $\mathrm{mm})$ are tested in this work. The heating rate is controlling with the power transformer (variac). A variable resistance was used to control The power input of the cartridge heater as shown in figure (3). Variable resistance can provide different voltage varies from $(0$ to $260 \mathrm{~V})$. A digital voltmeter and digital meter are used to measure the electrical voltage and, current.

\section{Materials used in preparing samples}

Five different samples of semi-spherical perlite expanded particles shown in figure (4) are used in this study. These samples are examined in the Pure Sciences lab of College of Education/Ibn Al-Haytham by X-Ray Diffraction device (XRD) to determine particle size according to the Scherrer equation as given in table (1). Scanning Electron Microscope (SEM) is used to determine image particle characterization as shown in figure (5).

\section{Instrumentation}

\section{Voltmeter}

The voltage provided to the heater was measured in the current work by voltmeter device which is shown in figure $(1, a)$. The voltage was measured to check the power input of the heater, accuracy of $( \pm 0.03 \mathrm{~V})$.

\section{Ameter}

The current used by the heater was measured by ameter accuracy of $( \pm 0.01 \mathrm{~A})$ shown in figure $(1, a)$.The current was measured to calculate the power input of the heater.

\section{Temperature measurements}

Twelve $\mathrm{K}$ type thermocouples are used to measure temperature range from $\left(20^{\circ} \mathrm{C}\right.$ to $200^{\circ} \mathrm{C}$ ). Five thermocouples are installed inside a plate heater (between heater cartridges) to measure the temperature. Two thermocouples (5 and 7) are used to measure the insulation upper surface (in contact with the hot surface of the heater) and two sensors (8 and 9) are located at insulation lower surface (in contact with steel plate surface). Three thermocouples $(10,11$ and 12) are used to measure the lower surface 
of the tested steel plate as shown in figure (6) and table (2). All these thermocouples are connected to 12 channels thermometers of $0.1^{\circ} \mathrm{C}$ resolution.

\section{Glass beaker}

The cup is a cylindrical container $(1000 \mathrm{ml})$ made of glass. The glass cup is used to determine the number of granular materials and also to mix it with white paint as shown in figure (7).The range in size is one liter and the beaker is accurate within $\sim 10 \%$.

\section{Preparation of thermal insulation samples}

Five different samples with different particle sizes are prepared in this study. Samples volumetric mixing percentage of components is displayed in the table (3). Perlite expanded particle material is mixed well with the white resin paint that is used in conventional LPG tanks to form the thermal coating insulation material. The coating steps of the tank wall sample by this mixture are:

1.Cleaning the surface of the tested plate by ethanol material before coating.

2.Mixing perlite expanded particles with paint resin according to the specified ratio.

3.Coating the surface of the tested steel plate evenly with the thermal insulation material.

4.All previous steps have been followed for each type of thermal insulation.

\section{Experimental procedure}

Below are the steps followed for each test:

1.Installing the thermocouples on the surface of the sample plate using thermal glue.

2.Connecting all the thermocouples to the data recorders, and checking the date and time stored.

3.Checking the devices (voltmeter, and ameter).

4.Turn on the power supply and (variac).

5.Increasing the power from zero to the required power input.

6.Setting the voltage variation device (variac) to the required power input

7.Read temperatures each $10 \mathrm{~min}$.

8.Record of the steel plate surface and heater temperatures until a steady-state is reached.

9.Change power input and repeat steps (5,6 and 7).

10. The procedure is repeated to measure another type of insulation material.

\section{DATA REDUCTION}

The electrical power supplied to the heater is calculated as:

$\mathrm{P}=\mathrm{V} . \mathrm{I}$

where

$\mathrm{I}=\operatorname{Current}(\mathrm{A})$

$\mathrm{V}=$ The voltage supplied to the heater $(\mathrm{V})$

The voltage values are selected from 50 to $70 \mathrm{~V}$ and the provided electrical power is $(6.5,12.6 \mathrm{~W})$. The surface area of the tested sample was $0.01 \mathrm{~m}^{2}$, which results in a heat flux of $\left(650,1260 \mathrm{~W} / \mathrm{m}^{2}\right)$. The heat flux subjected on the insulated plate is: Holman (2007)

$q=P / A$ 
Since heat transferred within the insulating coated layer is by conduction, it can be calculated according to Fourier's law as:

$\mathrm{q}=\mathrm{k} \frac{\Delta \mathrm{T}}{\mathrm{L}}$

where

$\mathrm{k}$ is thermal conductivity (W/m.K)

$\Delta \mathrm{T}$ is the temperature difference between upper and lower

$\mathrm{L}$ is coated layer thickness $(\mathrm{m})$

so the thermal conductivity of the insulation coated layer is evaluated as:

$\mathrm{k}=\frac{\mathrm{q}}{\Delta \mathrm{T} / \mathrm{L}}$

\section{ERROR ANALYSIS}

Thermal conductivity $(\mathrm{K})$ is a function of different variables namely: current, voltage, temperature, and sample thickness). The accuracy of the measurement parameters used in this work are given in Table (4). The percentage error of the thermal conductivity of materials is calculated as : Holman 2007

$\mathbf{w}_{\mathrm{K}}=\left[\left(\frac{\partial \mathrm{K}}{\partial \mathrm{I}} \mathbf{w}_{\mathrm{I}}\right)^{2}+\left(\frac{\partial \mathrm{K}}{\partial \mathrm{V}} \mathbf{w}_{\mathrm{V}}\right)^{2}+\left(\frac{\partial \mathrm{K}}{\partial \mathrm{T}} \mathbf{w}_{\mathrm{T}}\right)^{2}+\left(\frac{\partial \mathrm{K}}{\partial \mathrm{L}} \mathbf{w}_{\mathrm{L}}\right)^{2}\right]^{1 / 2}$

where $w_{k}$ is the uncertainty in the calculated thermal conductivity and $w_{\mathrm{I}}, w_{v}, \ldots, w_{T}$, $\mathrm{w}_{\mathrm{L}}$ is the uncertainty in the independent variables: current, voltage, temperature and thickness respectively. Their values are $1.75,4.5^{*} 10^{-3}, 1.575^{*} 10^{-2}, 0.63$, respectively. So the obtained uncertainty in conductivity is $1.16 \%$.

\section{RESULTS AND DISCUSSION}

Figures $(8,9,10,11,12)$ display the temperature average of the heater hot plate surface, the upper surface of the insulating layer and its lower surface for types of thermal insulation materials, which starts low and begins to rises gradually with passes heat flux of heater hot plate. Note that the higher temperature was for the heater surface followed by heater lower surface and plate upper surface of the thermal layer respectively. The heater acquires the heat from the hot plate that passes through a heater, followed by the upper surface of the thermal layer, where its temperature is less than the temperature of the heater surface where the upper surface of the thermal layer gets heat from the heater surface by conduction. The plate upper surface is the least temperature because it loses heat to the lower surface of the plate by conduction, which losses heat to the ambient by convection and radiation. Before operating the heating system, the temperature of the heater surface, heater lower surface and plate upper surface of the thermal layer is almost equal to the temperature of the laboratory. After operating heating system, its notice that the difference between the upper and lower surface of the insulation layer is small at the beginning of the experiment because the upper and lower surface is affected by laboratory temperatures so we did not notice the effect of the insulation layer, then that heat flux passes through it, where surface its temperature increases faster in comparison with upper and lower surfaces temperature. The temperature of the upper surface of the insulating layer follows the temperature of the heater hot plate. The temperature of the heater lower surface rises proportionally with the increase of heater surface temperature. It has been shown that increasing the value of heat flow, as well as increasing time, has increased the temperature. During the first hour of the test, the thermal response of the heater surface is very fast compared to the hot plate surface and the lower surface of the 
insulating layer. The thermal response of the insulating layer is slow as it acts as a shield and first receives the thermal effect from the hot plate. After two hours of the test, regular readings were obtained, where the upper surface of the plate reaches 60 ${ }^{\circ} \mathrm{C}$, while the hot plate heater reaches $90{ }^{\circ} \mathrm{C}$. After a period of time from starting the test, the upper and lower surface arrive in an approximately steady state. The convergence of steady-state temperature is reached after (170 to 240) minute for the accomplished tests, it is specified according to:

$\xi=\frac{\mathrm{T}^{\mathrm{new}}-\mathrm{T}^{\text {old }}}{\mathrm{T}^{\text {old }}} * 100 \%=0.5 \%$

Figure (8) shows the effect of type (I) of the temperature insulation layer on the insulation system. Type (I) of the insulation layer, the surface temperature distribution is shown in this figure, where the temperature reaches $70{ }^{\circ} \mathrm{C}$ at the upper surface of the insulation layer while $55{ }^{\circ} \mathrm{C}$ is reached the lower surface of thermal insulation. Where to reach a state of stability takes a long time. After two hours, temperature reading on surfaces reaches steady-state.

Figure (9) shows the second type of granule insulating material gives the lowest temperature difference on both ends of the sample, the temperature of the hot plate surface reaches $56{ }^{\circ} \mathrm{C}$ while the upper surface of insulation reaches $69{ }^{\circ} \mathrm{C}$. The results of these figures indicate that the granular size of the insulation material types (I, II and III) gives a temperature difference at both ends of the sample not exceeding $18{ }^{\circ} \mathrm{C}$. The reason is that these materials have a small diameter and are free of air gaps that enable them to reduce or delay heat transfer.

Figures $(10,11)$ show temperatures distribution on the (medium and large) expanded particle surfaces. The temperature difference on both ends of the insulation material reaches $20^{\circ} \mathrm{C}$ for the fourth type. Type $\mathrm{V}$ gave the best results as shown in figure (12) reaches $25^{\circ} \mathrm{C}$.

\section{Comparison of different types of thermal insulation diameters in thermal efficiency}

In this part, comparisons will be made for different thermal insulation diameters which are $(90.416,300.515,680.774,1211000,1861000 \mathrm{~nm})$ and the test was under power loads namely $\left(1260 \mathrm{~W} / \mathrm{m}^{2}\right)$.

Figure (13) display the temperature of the lower surface for different thermal insulation diameters, which starts low and begins to rises gradually with rises heat flux until arriving at stability after two hours of the test. Note that the higher temperature was for a fine expanded particle (a) followed by Glass expanded particle, fine expanded particle (b), medium expanded particle and large expanded particle respectively. When the diameter of the insulating material becomes smaller, the heat transfer through the thermal insulation layer increases. A comparison of these figures indicates that increasing the expanded particle size of the insulation increases the difference in temperatures on both ends of the sample, where the fifth type of granule insulating material gave the highest temperature difference on both ends of the sample. When the thermal insulation type $(\mathrm{V})$ added at the upper surface of the plate the heat transfer decreased. The thermal conductivity values of tested specimens are analyzed based on specimen diameters, where thermal conductivity for the first three types is $\left(0.42 \mathrm{~W} / \mathrm{m} .{ }^{\circ} \mathrm{C}\right)$. The thermal conductivity for the fourth and fifth types is $(0.25$ $\mathrm{W} / \mathrm{m} .{ }^{\circ} \mathrm{C}$ ). The five types of thermal insulation give lower heat conduction compared to other types because of less thermal conductivity. The results showed that the thermal conductivity decreases with increasing the granular size of the insulating materials. The following results showed that the lowest value of thermal conductivity was 
obtained when samples were selected with large expanded particle size compared to samples with small size. As the diameter of the sample molecules increases, the air gaps in the molecules of the material increase, reducing thermal conductivity. The fourth and fifth type of insulation gives better results than the previous types mentioned. As for the fifth type, the results were the best compared to all the previous types measured. The reason the formation of the expanded particle, which helps in the expulsion of heat and creates an insulating layer suitable for many applications. Experimental results reveal that the particle size of the granule insulation can affect the insulation efficiency.

The purpose of using two states of heat supply, for the purpose of representing solar radiation is similar to the solar radiation that falls on Iraqi airspace. When using the power supply $\left(650 \mathrm{~W} / \mathrm{m}^{2}\right)$, we obtain results for thermal insulation similar to the first case of the test but notice in the second case it takes longer to heat the surface of the insulation material and reach a state of stability (that is, obtain similar results during the test time) as shown in figure (14).

\section{CONCLUSIONS}

Based on the previously discussed results the following conclusions can be extracted:

1. Experimental work was carried out to measure the thermal conductivity of semispherical particles when the particle size of the material changes as well as when the temperature changes.

2. The thermal conductivity of material has been calculated at a steady state.

3.The results showed that the thermal conductivity decreases with increasing the granular size of the insulating materials.

4.The lowest thermal conductivity was obtained when the material of large size was selected.

Table (1): Specifications of thermal insulation particles

\begin{tabular}{|c|c|c|}
\hline Type & Name & Diameter (nm) \\
\hline I & Glass expanded particles & $56.499-68.774$ \\
\hline II & Very Fine expanded particle (a) & $80.597-90.416$ \\
\hline III & Fine expanded particle (b) & $290.39-300.515$ \\
\hline IV & Medium expanded particles & $7.24 \mathrm{E} 5-1.211 \mathrm{E} 6$ \\
\hline V & Large expanded particles & $1.604 \mathrm{E} 6-1.861 \mathrm{E} 6$ \\
\hline
\end{tabular}

Table (2): Thermocouples sites.

\begin{tabular}{|c|l|}
\hline Number & Description \\
\hline $1-5$ & Positions of thermocouples of the hot plate heater \\
\hline $6-7$ & Positions between the heater and upper surface of the insulation coating layer \\
\hline $8-9$ & Positions between lower surface of the insulated sample and upper surface of steel plate \\
\hline $10-12$ & Positions between the lower surface of the steel plate and room temperature \\
\hline
\end{tabular}


Table (3): The volumetric percentage of Perlite expanded particle and resin paint in the insulation layer.

\begin{tabular}{|c|c|c|}
\hline Type & $\begin{array}{c}\text { Perlite expanded } \\
\text { particle \% }\end{array}$ & Paint \% \\
\hline I & $50 \%$ & $50 \%$ \\
\hline II & $60 \%$ & $40 \%$ \\
\hline III & $60 \%$ & $50 \%$ \\
\hline & & \\
\hline IV & $50 \%$ & $50 \%$ \\
\hline V & $40 \%$ & $60 \%$ \\
\hline
\end{tabular}

Table (4): Accuracy of the adopted parameters used in the calculation

\begin{tabular}{|l|l|l|l|l|}
\hline Parameter & Temperature & Voltmeter & Ameter & Thickness \\
\hline Accuracy & $\pm 0.1^{\circ} \mathrm{C}$ & $\pm 0.03 \mathrm{~V}$ & $\pm 0.01 \mathrm{~A}$ & 0.01 \\
\hline
\end{tabular}

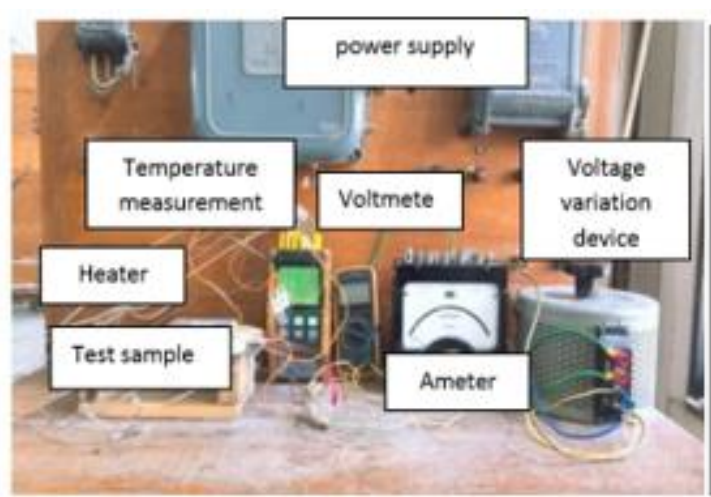

(a)

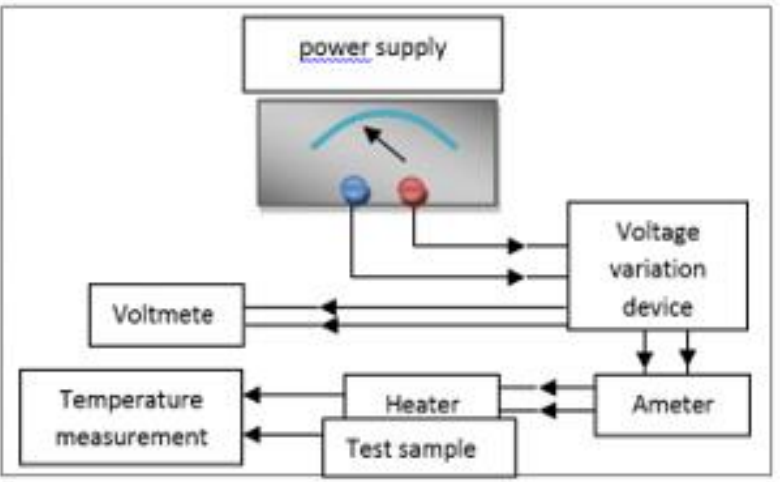

(b)

Fig. (1) Experimental setup (a) Photograph, (b) Schematic diagram.

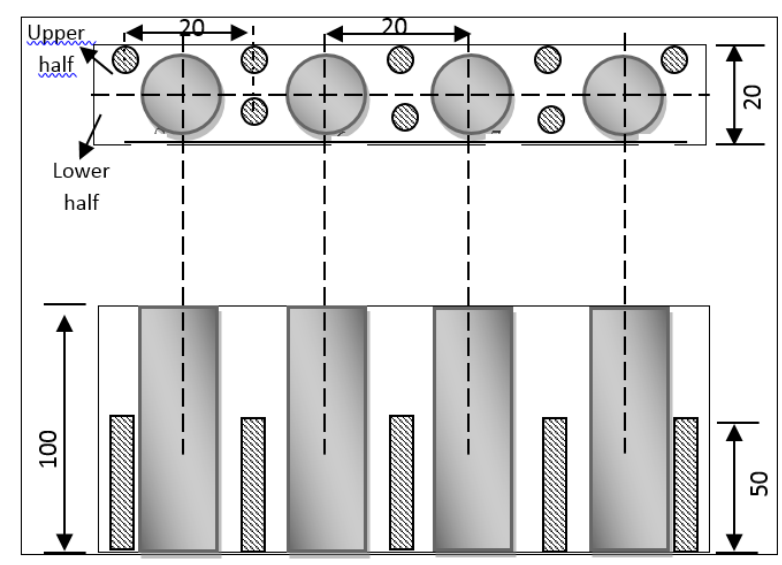

Fig. (2) Schematic diagram of plate heater and thermocouple.

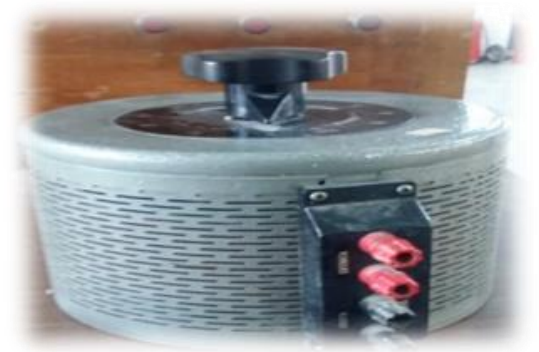

Fig. (3): Voltage variation device(Variac). 


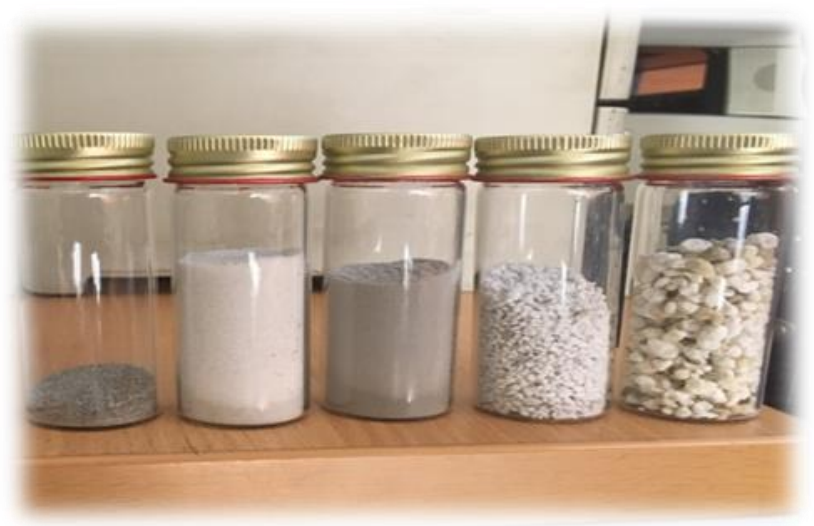

Fig. (4) Thermal insulation types.
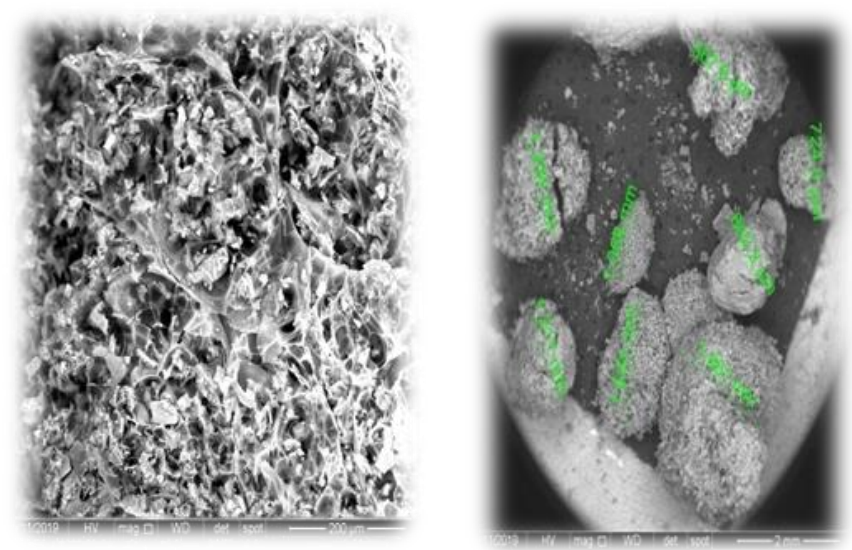

Fig. (5) Scanning Electron Microscopy (SEM)

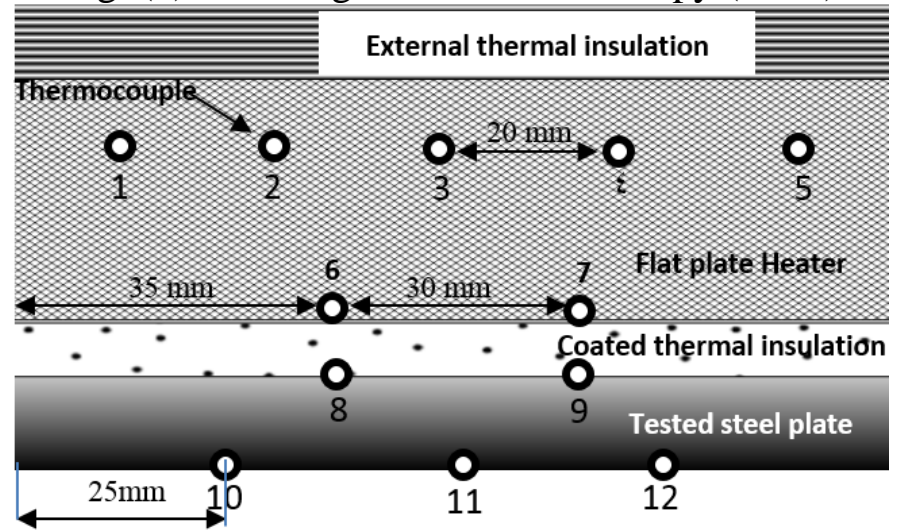

Fig. (6) Distribution of temperature sensors in the tested sample 


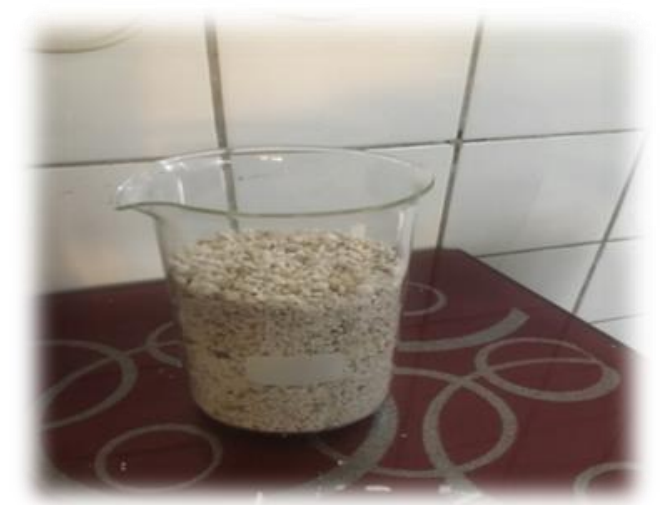

Fig. (7) Glass beaker

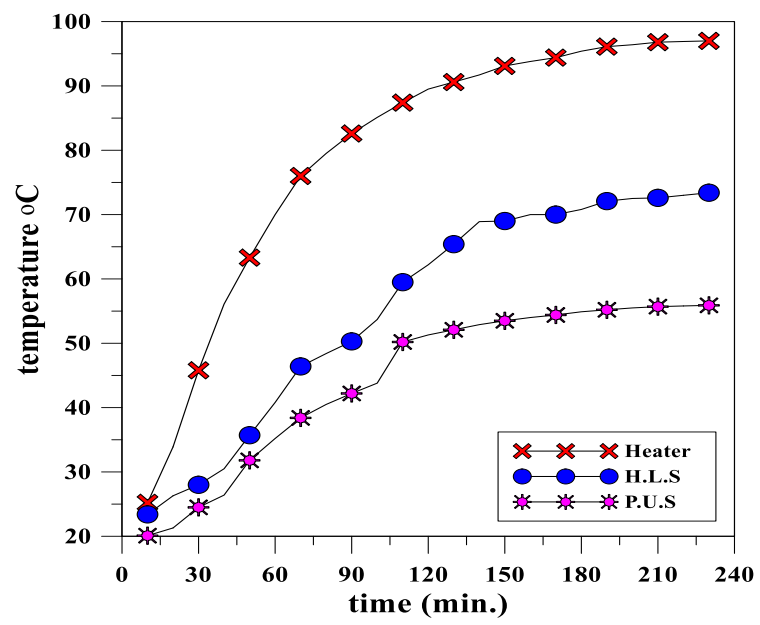

Fig. (8) Temperature history of heater hot plate and plate surface coated with Type (I) Glass expanded particles.

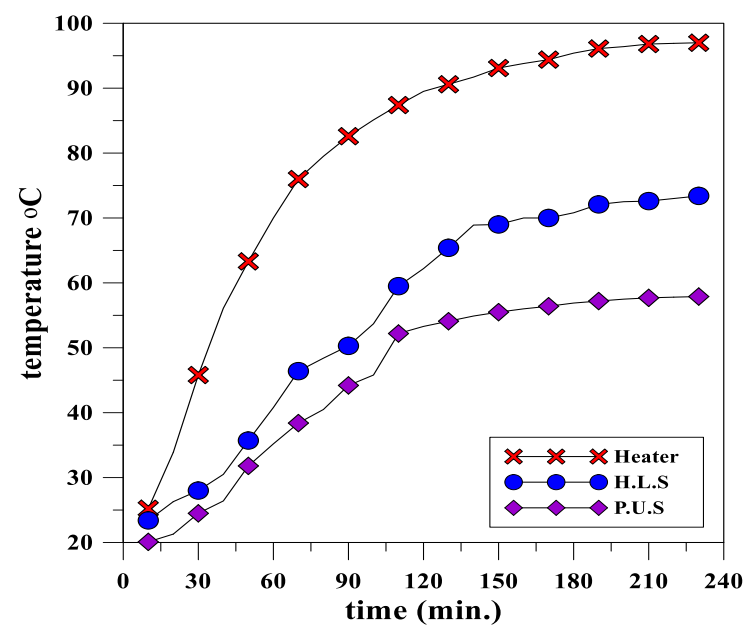

Fig. (9) Temperature history of heater hot plate and plate surface coated with Type (II) very fine expanded particle. 


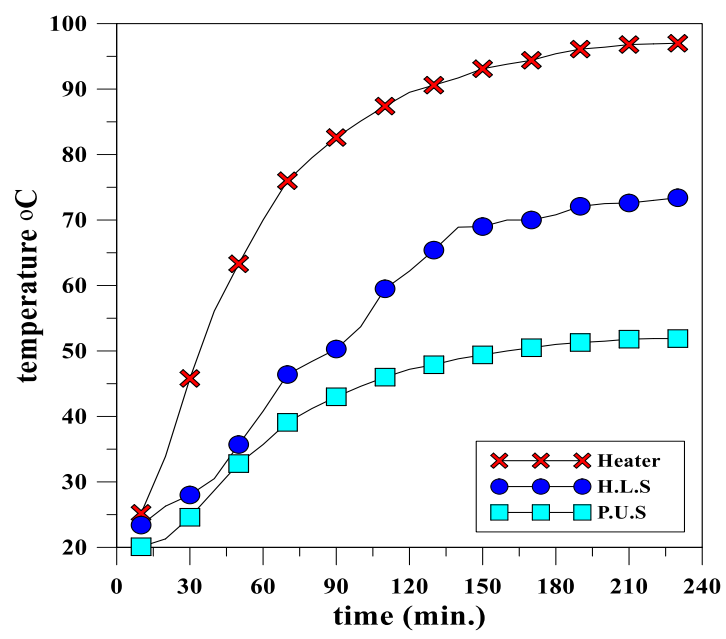

Fig. (10) Temperature history of heater hot plate and plate surface coated with Type (III) Fine expanded particle.

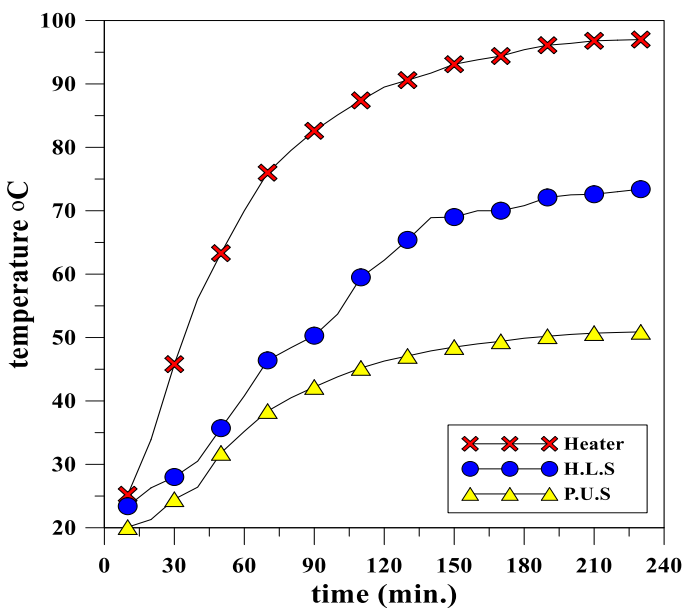

Fig. (11) Temperature history of heater hot plate and plate surface coated with Type (IV) Medium expanded particles.

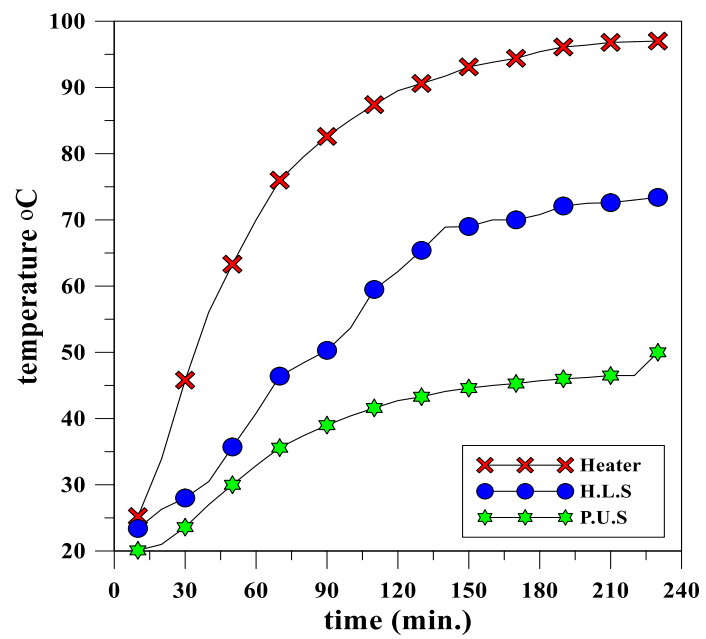

Fig. (12) Temperature history of heater hot plate and plate surface coated with Types (V) Large expanded particles. 


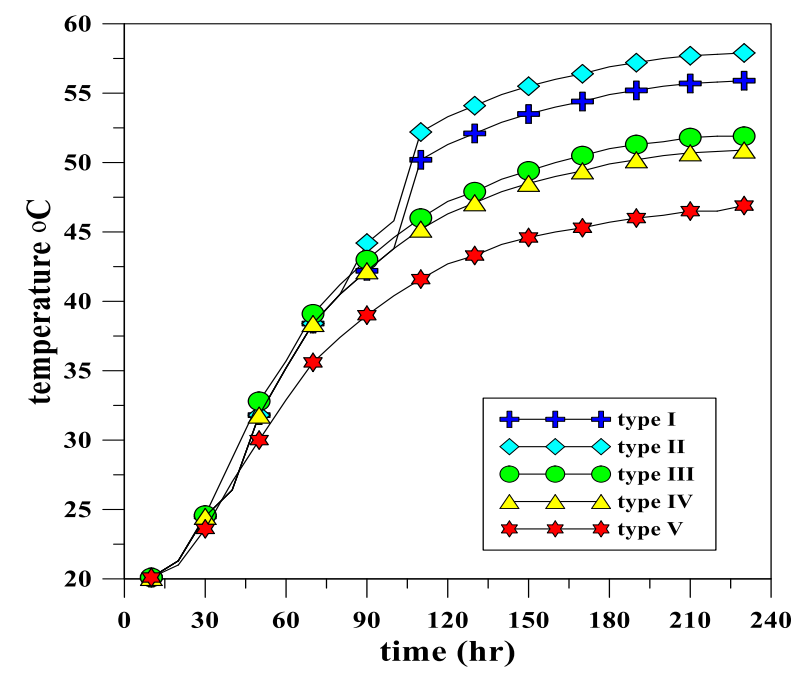

Fig. (13): History of the temperature of the lower surface for different thermal insulations under $1260 \mathrm{Wm}^{2}$.

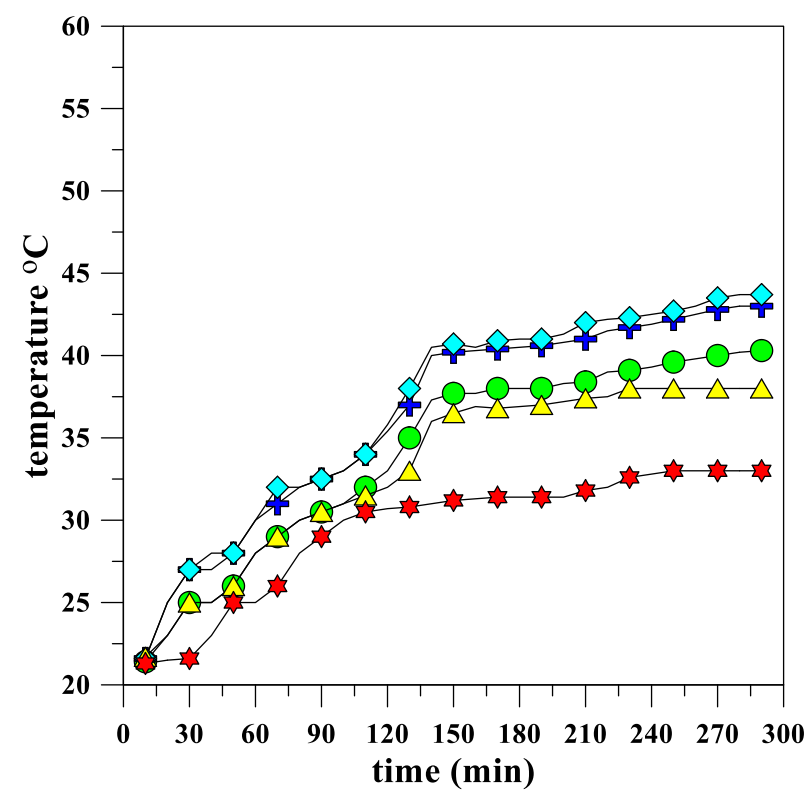

Fig. (14) History of the temperature of the lower surface for different thermal insulations under $650 \mathrm{~W} / \mathrm{m}^{2}$.

\section{REFERENCES}

Droste B. and Schoen W., "Full-Scale fire tests with unprotected and thermal insulation LPG storage tanks", Journal of Hazardous Material, Vol. 20, pp. 41-53, 1988.

Fesmire J.E., "Layered composite thermal insulation system for nonvacuum cryogenic applications", Cryogenics, Vol. 74, pp. 154-165, 2016.

Holman, J. P, " Heat Transfer, $9^{\text {th }}$ edition Tuta McGraw-Hill Publishing Company Limited, 2007.

Joseph J., Agrawal G., Kumar D., Pisharady J.C., Sunil Kumar S., "Effect of insulation thickness on pressure evolution and thermal stratification in a cryogenic tank", Applied Thermal Engineering, Vol. 111, pp. 1629-1639, 2017. 
Landucci G., Molag M., Cozzani V., "Modeling the performance of coating LPG tanks engulfed in fires", Journal of Hazardous Material, Vol. 172, pp. 447-456, 2009.

Landucci G., Molag M., Reminders J., Cozzani V., "Experimental and analytical investigation of thermal coating effectiveness for $3 \mathrm{~m}^{3}$ LPG tanks engulfed by fire", Journal of Hazardous Materials, Vol. 161, pp. 1182-1192, 2009.

Niu W.C., Li G.L., Ju Y.L., Fu Y.Z. , "Design and analysis of the thermal insulation system for a new independent type B LNG carrier" , Ocean Engineering , Vol. 142 , pp. 51-61, 2017.

Paltrinieri N., Landucci G., Molag M., Bonvicini S., Spadoni G., Cozzani V., "Risk reduction in road and rail LPG transportation by passive fire protection", Journal of Hazardous Material, Vol. 167, pp. 332-4344, 2009.

Sun D., Huang G., Jiang J., Zhang M., Wang Z. , "Influence of the protective layer of polyvinylchloride resin on the failure of LPG vessel caused by heat radiation", Procedia Engineering, Vol. 62, pp. 564-572, 2013.

Zhang J., Chen L., Cui C., Guo J., Zhu W., Zhou Y., Wang J., "Experimental study on composite insulation system of spray-on foam insulation and variable density multilayer insulation", Applied Thermal Engineering, Vol. 130, pp. 161-168, 2018. 